\title{
Pain-related and negative semantic priming enhances perceived pain intensity
}

\author{
Maria Richter $\mathrm{PhD}^{1,2 *}$, Christoph Schroeter MSc ${ }^{1 *}$, Theresa Puensch MSc${ }^{1}$, Thomas Straube $\mathrm{PhD}^{1,3}$, \\ Holger Hecht MSc${ }^{1}$, Alexander Ritter MSc${ }^{1}$, Wolfgang HR Miltner PhD ${ }^{1}$, Thomas Weiss MD PhD ${ }^{1}$
}

M Richter, C Schroeter, T Puensch, et al. Pain-related and negative semantic priming enhances perceived pain intensity. Pain Res Manag 2014;19(2):69-74.

BACKGROUND: Negative affective and pain-related cues, such as pictures or words, have been shown to act as primes and enhance the perceived intensity of subsequent painful events. For pain-related semantic primes, it remains unclear whether this effect depends on negative valence itself or, specifically, on the pain-relatedness of the words. (pain-unrelated) and neutral semantic primes on the perception of subsequent noxious target stimuli.

METHODS: Pain ratings in response to noxious electrical stimulation of light and moderate intensity were examined in 39 healthy subjects after subjects were exposed to semantic primes of different meaning and valence (pain-related, negative, positive and neutral adjectives) presented with different interstimulus intervals $(0 \mathrm{~ms}, 500 \mathrm{~ms}$ and $1500 \mathrm{~ms})$.

RESULTS: Increased pain ratings of noxious stimuli were observed following pain-related and negative compared with neutral primes.

DISCUSSION: The results support the motivational priming theory for semantic stimuli, indicating that affectively negative semantic primes increase subjective pain intensity. However, a specific pain-related priming effect was not reliably demonstrated. Additionally, it is shown that experimental parameters (ie, stimulus intensity and interstimulus interval) modify the extent of negative and pain-related semantic priming.

CONCLUSIONS: Verbal priming plays a role for the perception of noxious stimuli in a time-dependent manner.

Key Words: Affective words; Electrical stimulation; Pain ratings; Pain words; Semantic priming

$\mathrm{T}$ he perception and processing of painful events is modulated by environmental and interpersonal conditions such as attention, anticipation and negative mood (1-7). In recent studies, different affective states were induced by pictures, video sequences or odours before noxious stimulation, showing that such negative emotional priming is associated with enhanced physiological responses and increased pain ratings to noxious target stimuli (8-12), according to the assumptions of the motivational priming theory (13). Furthermore, a larger negative priming effect was observed when affective pictures were pain-related in comparison with neutral or negative, pain-unrelated pictures $(14,15)$. Consequently, the concept of associative memory networks that establish during synchronization of cell assemblies (16) may provide an additional theoretical background to explain pain-related priming $(17,18)$. The processing of action words activates a specific set of neurons including the sensorimotor region of the body part involved in this action $(19,20)$. Accordantly, it was recently reported that pain-related words specifically activate several pain-processing brain regions (21-23). In fact, written word primes induced the strongest cross-modal priming effect, as indicated by enhanced P300 amplitudes (24). Accordingly,
OBJECTIVES: To investigate the effect of pain-related, negative affective

\section{L'amorçage sémantique lié à la douleur et négatif favorise l'intensité perçue de la douleur}

HISTORIQUE : Il est démontré que des indices affectifs négatifs et liés à la douleur, tels que des images ou des mots, agissent comme des amorces et accroissent l'intensité perçue d'événements douloureux subséquents. Pour ce qui est des amorces sémantiques liées à la douleur, on ne sait pas si cet effet dépend d'une valence négative ou, plus précisément, du lien des mots avec la douleur.

OBJECTIFS : Examiner l'effet d'amorces sémantiques liées à la douleur, affectives négatives (sans lien avec la douleur) et neutres sur la perception de stimuli ciblés douloureux administrés par la suite.

MÉTHODOLOGIE : Les chercheurs ont examiné les évaluations de la douleur en réponse à une stimulation électrique douloureuse d'intensité légère à modérée chez 39 sujets en santé après les avoir exposés à un amorçage sémantique aux diverses significations et valences (adjectifs liés à la douleur, négatifs, positifs et neutres), présenté à divers intervalles entre les stimuli ( $0 \mathrm{~ms}, 500 \mathrm{~ms}$ et $1500 \mathrm{~ms}$ ).

RÉSULTATS : Les chercheurs ont observé des évaluations plus élevées de la douleur après des amorces liées à la douleur ou des amorces négatives par rapport à des amorces neutres.

EXPOSÉ : Les résultats corroborent la théorie motivationnelle de l'amorçage par stimuli sémantiques, selon laquelle des amorces sémantiques négatives sur le plan affectif accroissent l'intensité subjective de la douleur. Cependant, l'effet précis de l'amorçage lié à la douleur n'a pas été démontré de manière fiable. De plus, des paramètres expérimentaux, c'est-à-dire l'intensité du stimulus et l'intervalle entre les stimuli, modifient l'étendue de l'amorçage sémantique négatif et lié à la douleur.

CONCLUSIONS : L'amorçage verbal joue un rôle dans la perception des stimuli douloureux en fonction du temps.

larger P300 amplitudes of laser-evoked potentials were found during pain-related compared with neutral semantic priming $(25,26)$. These observations indicate that using semantic primes may be a suitable method to study the effects of priming within pain-associated neural networks of the human brain. However, it remains unclear whether the increased response to noxious stimuli following such primes is due to the negative valence of primes or whether the pain relatedness of such primes exerts a specific priming effect. It is also unclear whether there is a modulating effect of stimulus intensity and interstimulus interval (ISI) between prime and target stimulus. Recent studies have solely investigated the effect of priming when noxious stimuli were applied immediately after $(10,27)$ or during $(8,25,26,28)$ prime presentation, and when pain was fixed to a single stimulus intensity (29).

The cortical processing of visually presented semantic stimuli can be subdivided into several steps, beginning with the visual analysis of orthographical features at approximately $100 \mathrm{~ms}$ to $200 \mathrm{~ms}$ after word onset (30). Semantic access and comprehension were demonstrated to be organized between $200 \mathrm{~ms}$ and $300 \mathrm{~ms}$, and attention processes and contextual analyses follow between $300 \mathrm{~ms}$ and $400 \mathrm{~ms}$ after stimulus onset (31,32). Between $450 \mathrm{~ms}$ and $1000 \mathrm{~ms}$ or even later, sustained

*These authors contributed equally to this work

${ }^{1}$ Department of Psychology, Biological and Clinical Psychology, Friedrich Schiller University; ${ }^{2}$ Department of Psychiatry, University Hospital Jena, Jena; ${ }^{3}$ Department of Medical Psychology, University Munster, Munster, Germany

Correspondence: Dr Thomas Weiss, Department of Psychology, Friedrich Schiller University, Am Steiger 3/1, D-07743 Jena, Germany.

Telephone 49-3641-945143, fax 49-3641-945142, e-mail thomas.weiss@uni-jena.de 
processing in memory structures and the organization of behavioural responses to word stimuli have been suggested $(31,33,34)$. Thus, the prime is stressing working memory and initiates response selection. Given that the central processing of visually presented semantic stimuli involves several distinct steps, the priming effect of those stimuli on the processing of the succeeding noxious stimulus may critically depend on the ISI between presented word and noxious stimulus.

Furthermore, the intensity of the noxious stimulus appears to be an important moderator for the interaction between prime and stimulus. Godinho et al (27) showed a distinct negative priming effect for clearly painful electrical stimulation but not for lower stimulation intensities slightly beyond the pain threshold. Kenntner-Mabiala and Pauli (9) presented a significant affective priming effect of negative pictures, compared with neutral pictures, for mild painful electrical stimulation.

We hypothesized that both pain-related and negative painunrelated primes increase the pain rating in response to subsequent noxious stimuli compared with neutral primes. Furthermore, we hypothesized that pain-related semantic primes compared with painunrelated, negative primes further increase those pain ratings. We also aimed to investigate whether these effects depend on the intensity of noxious stimulation and on the duration of the ISI between prime and noxious stimulus.

\section{Subjects}

Thirty-nine right-handed healthy volunteers (19 female and 20 male, mean $[ \pm \mathrm{SD}$ ] age $21.1 \pm 2.1$ years) participated in the present experiment. Participants were students recruited via announcements on university billboards and mailing lists. All subjects were native German speakers and provided informed consent for participation, in accordance with to the Declaration of Helsinki. Subjects were free of pain medication and were not experiencing any type of acute or chronic pain. The Beck Depression Inventory (BDI-2) (35) was used to assess depressive symptoms and a life pain questionnaire with Likert scales (scores of 0 to 10 ) was used to assess participants' previous pain experience. None of the subjects was excluded because of fulfilling the a priori criteria of BDI- 2 scores $>18$ or previous critical pain experiences (eg, traumatic injuries or indices for chronic pain experiences). The mean BDI-2 score was $6.65 \pm 3.07$ and, according to an additional clinical interview, none of the subjects showed depressive symptoms.

\section{Pain stimuli}

Electrical stimuli consisted of rectangular pulses (20 ms duration) generated by a constant current stimulator (DS7H; Digitimer, United Kingdom). Intracutaneous stimuli were applied to the tip of the middle finger of the left hand $(3,5,36,37)$; an isolated golden pin electrode (diameter $0.95 \mathrm{~mm}$; length $1 \mathrm{~mm}$ ) was inserted into a small epidermal cavity of $1 \mathrm{~mm}$ diameter and approximately $1 \mathrm{~mm}$ depth and fixed with adhesive tape. Care was taken not to cause any bleeding. The purpose of this preparation was to reduce skin resistance and, thus, the current necessary to elicit a pain sensation. A flexible stainless steel electrode, fixed loosely around the first finger joint, served as a reference electrode.

\section{Study design}

Individual stimulus-response curves were determined before the experiment by applying five series of electrical stimuli with ascending and descending intensity in increments of $0.5 \mathrm{~mA}$. Maximum stimulation intensity before starting the descending series was fixed to a rating of $\geq 50$, indicating strong pain. The intensity was then reduced until the participant rated the stimulus as not perceived (0). Participants were asked to rate each stimulus on a modified Ellermeier scale ( 0 , no sensation; 1 to 10 , just perceived but not painful; 11 to 20 , clearly perceived but not painful; 21 to 30 , very mildly painful; 31 to 40 , mildly painful, 41 to 50 , moderately painful; 51 to 60 , strongly painful, 61 to 70 very strongly painful; and $\geq 71$, not tolerable; this part of the scale is open at its upper end) (38). The scale was presented on the same computer screen on which adjectives were presented each time after noxious stimulation (Figure 1). According to Ellermeier et al (38), subjects have first to choose a verbal categorization of stimulation (eg, mildly painful) followed by a more fine-graded numerical decision within the range belonging to the verbal categorization (ie, for the verbal category 'mildly painful' in the range between 31 and 40). This scale has been shown to be valid, reliable and even equidistant concerning physical stimuli $(38,39)$. Subjects were prompted to give only the numerical rating verbally. Mean stimulus intensities rated as very mildly painful $(\operatorname{Int} 1=25)$ and moderately painful (Int2 $=45$ ) were chosen for the experiment. Usually, short phasic nociceptive stimuli tend to habituate (40); however, there are rare cases of sensitization. To protect subjects from strong stimulations, an algorithm that finished the experiment whenever participants consecutively rated three stimuli $\geq 50$ was introduced. According to this criterion, one subject showing sensitization effects was not included in the analyses.

Based on a previous study, a total of 40 adjectives were used as semantic primes: 10 pain related, 10 negative, 10 positive and 10 neutral (23). Words between categories were matched according to their word frequencies (using Cosmas Version 3.6.1, www.ids-mannheim.de/ cosmas2) and lengths. For this purpose, groups of four words (one of each category) were constructed. Within these groups, word length and number of syllables were matched. Furthermore, word frequency was matched by the number of citations in German publications according to the COSMAS program. In rare cases, where matching was not perfect, care was taken that there was no statistical difference between categories in any of the matched parameters. Finally, painrelated and negative words were balanced according to their valence and arousal qualities. For this reason, the words were rated regarding valance and arousal on Likert scales (scored from 0 to 10) by 28 subjects during a preliminary study. Subseqently, matching pairs of words were selected as described in Richter et al (23). Positive adjectives were presented to counteract an affective bias toward negative mood during the experiment.

Subjects were paid $€ 6 / \mathrm{h}$ for participation. To increase participants' mental effort to attend to and process the semantic primes and to minimize error rates, subjects were informed that they could earn an extra $€ 10$ if they correctly repeated $>90 \%$ of the words presented during the experiment. This additional payment was announced at the beginning of the experiment to ensure that the participants attentively processed the semantic stimuli. Primes were presented in a pseudorandomized order for $300 \mathrm{~ms}$ each, and each prime was followed by one of another descriptor category to prevent summation effects. Subjects were instructed to silently read the word primes on a computer screen. Coincident with switching off the prime (ISI $0 \mathrm{~ms}$ ) or shortly after the end of representation of the prime on the screen (ISI $500 \mathrm{~ms}$ or $1500 \mathrm{~ms}$ ), an electrical stimulus of predetermined pain intensity ('mildly painful' [Int1] or 'moderately painful' [Int2]) was applied (Figure 1). A maximum of three stimuli of the same intensity were presented consecutively to reduce possible anchor effects. The ISI between primes and noxious target stimuli was varied randomly among the three ISIs. After each noxious stimulus, the rating scale presented on the computer screen and subjects were asked to rate the intensity of the stimulus verbally. Thereafter, they were requested to repeat the prime verbally (Figure 1). After $3 \mathrm{~s}$, the next trial started. During this time, the experimenter entered the rating and the correctness of the prime repetition on the keyboard. A total of 240 trials were conducted (ie, each prime was repeated six times throughout the experiment). The whole experiment was controlled by the software Presentation (version 14.5, Neurobehavioral Systems Inc, USA).

\section{Data analysis}

To test the two main hypotheses, a repeated-measures ANOVA with three within-subject factors (Category $\times$ Intensity $\times$ ISI) was applied. When appropriate, degrees of freedom were corrected by the Greenhouse-Geisser procedure to account for violations of sphericity. 


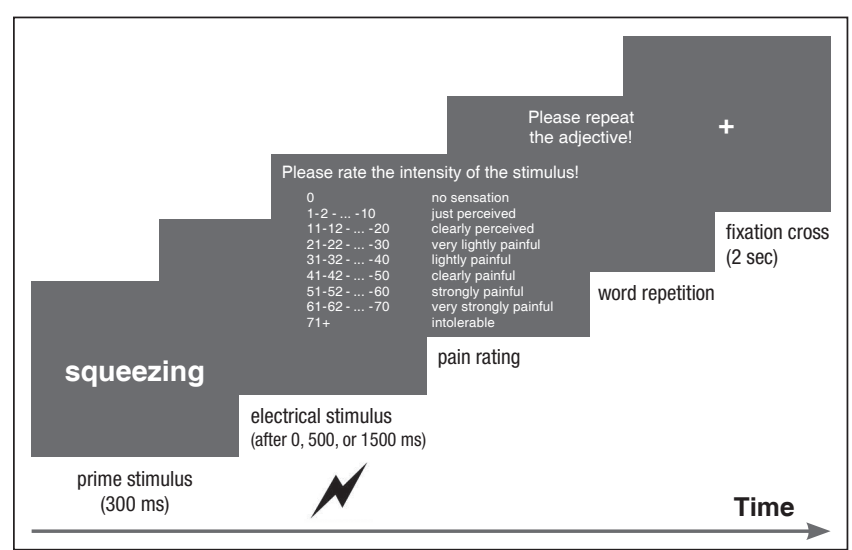

Figure 1) Design of experimental trials (example translated from German to English for illustration)

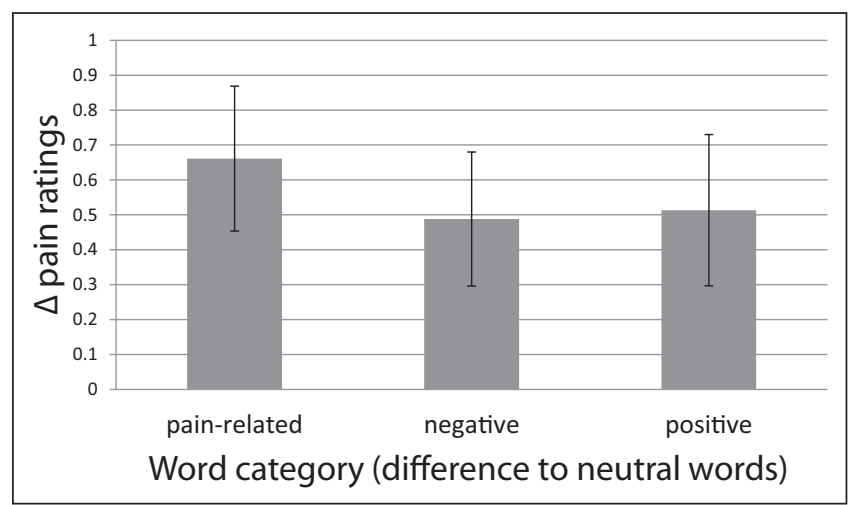

Figure 2 ) Mean differences in pain ratings ( $\Delta$ pain ratings) and standard errors to noxious stimuli in dependence of the primed adjectives (factor word Category) shown as differences to neutral adjectives

The 'Category' factor included four types of adjectives used as primes (pain-related, negative, neutral and positive); 'Intensity' included the two intensities of the electrical stimulation (Int1 and Int2); and 'ISI' comprised three levels (ISI 0 [0 ms], ISI 500 [500 ms] and ISI 1500 $[1500 \mathrm{~ms}])$. For significant main effects, post hoc $t$ tests for paired samples were calculated according to the hypotheses (two-tailed, Bonferroni corrected). These analyses were followed by contrast analyses modelling simple interaction and second-order simple main effects. Finally, $t$ tests for paired samples were used to test relevant differences between categories as a function of ISI and Intensity (two-tailed, Bonferroni corrected). In addition, the number of false prime repetitions during the experiment was also compared among word categories using an ANOVA for repeated measures.

\section{RESULTS}

ANOVA revealed significant main effects for Category $(F[3,114]=2.99$; $\left.\mathrm{P}=0.034 ; \eta_{\mathrm{p}}{ }^{2}=0.07\right)$ and Intensity $(\mathrm{F}[1,38]=167.18 ; \mathrm{P}<0.001$; $\left.\eta_{p}{ }^{2}=0.82\right)$ as well as significant interactions for Category $\times$ Intensity $\left(\mathrm{F}[3, ; 114]=8.39 ; \mathrm{P}<0.001 ; \eta_{\mathrm{p}}{ }^{2}=0.18\right)$, Category $\times$ ISI $(\mathrm{F}[6,228]=4.28$; $\left.\mathrm{P}<0.001 ; \eta_{\mathrm{p}_{2}}{ }^{2}=0.11\right)$ and Category $\times$ Intensity $\times$ ISI $(\mathrm{F}[6,228]=2.47$; $\mathrm{P}=0.043 ; \eta_{\mathrm{p}}^{2}=0.06$ ).

\section{Main effects}

$T$ tests between the levels of factor Category showed significant differences for pain versus neutral $(t=3.18 ; \mathrm{P}=0.009)$ and negative versus neutral $(t=2.54 ; \mathrm{P}=0.046)$ (Figure 2$)$. Mean $( \pm \mathrm{SE}$ ) intensity rating scores of noxious stimuli were $31.11 \pm 1.09$ following pain-related primes, $30.94 \pm 1.08$ following negative, $30.45 \pm 1.05$ following neutral and $30.96 \pm 1.05$ following positive primes. Factor Intensity has only two levels; therefore, the main effect reported above indicates a

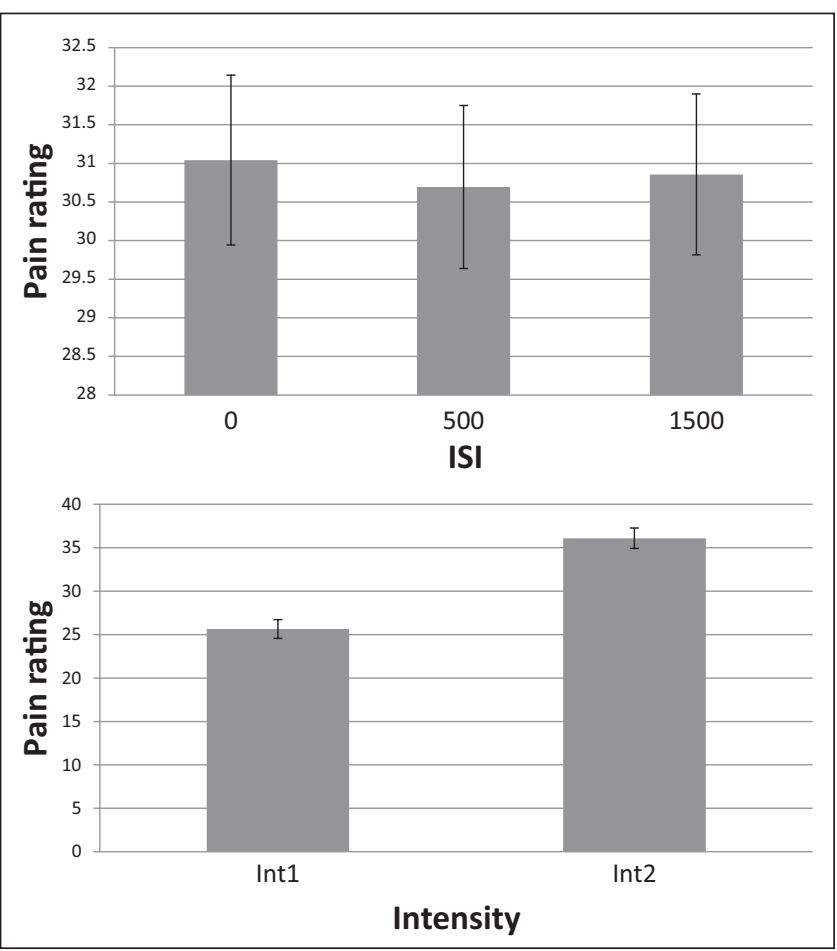

Figure 3) Mean pain ratings and standard errors to noxious stimuli in dependence of the interstimulus interval (ISI) and the intensity of stimulation

significant contrast in Int 2 versus Int1, with a mean intensity of 25.64 \pm 1.09 for Int1 and 36.09 \pm 1.18 for Int2 (Figure 3).

With regard to factor ISI, no significant difference of intensity ratings were found.

\section{Interactions}

With respect to the threefold interaction, simple interaction effect analyses were first conducted. Therefore, the simple interaction effect Category $\times$ ISI were analyzed for each of the two levels of Intensity. For Int1, this effect was not significant. In contrast, the analysis for Int2 revealed a significant simple interaction effect between these two factors $\left(F[6,33]=9.32 ; \mathrm{P}<0.001 ; \eta_{\mathrm{p}}{ }^{2}=0.63\right)$. To further investigate this simple interaction effect, second-order simple main effect analyses of the factor Category were conducted for each level of ISI within Int2. A significant second-order simple main effect was found for ISI 0 $\left(\mathrm{F}[3,36]=5.87 ; \mathrm{P}=0.007 ; \eta_{\mathrm{p}}{ }^{2}=0.33\right)$ and ISI $500(\mathrm{~F}[3,36]=16.81$; $\left.\mathrm{P}<0.001 ; \eta_{\mathrm{p}}{ }^{2}=0.58\right)$, but not for ISI 1500 . The differences between categories were analysed by separate post hoc $t$ tests for Int2 as a function of ISI. For ISI 0, significant differences between pain versus neutral $(t=2.90 ; \mathrm{P}=0.038)$, negative versus neutral $(t=2.85 ; \mathrm{P}=0.042)$ and pain versus positive $(t=4.28 ; \mathrm{P}=0.001)$ were observed. For ISI 500 , significant differences for pain versus neutral ( $t=3.42 ; \mathrm{P}=0.009)$, negative versus neutral $(t=4.50 ; \mathrm{P}<0.001)$ and neutral versus positive $(t=07.03 ; \mathrm{P}<0.001)$ were revealed. The contrast in pain versus negative failed to reach significance for all ISIs. Means and SDs for all conditions are listed in Table 1. Figure 4 presents means and SEs for the above-mentioned triple interaction.

During the experiment, a relatively low number of false prime repetitions occurred with mean $( \pm \mathrm{SE}$ ) of $3.15 \pm 0.50$ for pain primes, $3.33 \pm 0.50$ for negative, $1.46 \pm 0.30$ for neutral and $3.00 \pm 0.43$ for positive primes, indicating that the task was feasible for all participants. ANOVA of false repetitions revealed a significant main effect for Category $(F[3,114]=7.15 ; \mathrm{P}=0.001) . t$ tests indicated a significant differences between pain versus neutral $(t=4.96 ; \mathrm{P}<0.001)$, negative versus neutral $(t=4.00 ; \mathrm{P}=0.002)$ and neutral versus positive $(t=-3.59$; $\mathrm{P}=0.006)$. 
TABLE 1

Mean pain ratings depending on the factors Intensity, word Category and interstimulus interval (ISI)

\begin{tabular}{llccc}
\hline & Word & \multicolumn{3}{c}{ ISI } \\
\cline { 2 - 4 } & category & $\mathbf{0 ~} \mathbf{~ s}$ & $\mathbf{5 0 0} \mathbf{~ m s}$ & $\mathbf{1 5 0 0} \mathbf{~ m s}$ \\
\hline Intensity 1 = 25 & Pain-related & $25.93 \pm 7.15$ & $25.55 \pm 7.06$ & $25.40 \pm 7.50$ \\
& Negative & $25.37 \pm 7.38$ & $25.16 \pm 6.67$ & $25.92 \pm 7.64$ \\
& Neutral & $26.77 \pm 7.71$ & $25.09 \pm 7.29$ & $25.14 \pm 5.96$ \\
Intensity 2 = 45 & Positive & $25.87 \pm 6.55$ & $26.21 \pm 7.35$ & $25.27 \pm 7.15$ \\
& Pain-related & $37.13 \pm 8.36$ & $35.98 \pm 7.44$ & $36.66 \pm 7.57$ \\
& Negative & $36.56 \pm 7.82$ & $36.20 \pm 7.70$ & $36.41 \pm 7.70$ \\
& Neutral & $35.30 \pm 7.61$ & $34.41 \pm 7.28$ & $36.00 \pm 7.35$ \\
& Positive & $35.40 \pm 7.77$ & $36.96 \pm 7.75$ & $36.06 \pm 7.04$ \\
\hline
\end{tabular}

Data presented as mean $\pm S D$

\section{DISCUSSION}

We hypothesized that semantic priming with pain-related and negative word primes would result in stronger pain ratings to subsequent noxious target stimuli than priming with neutral words. Furthermore, we hypothesized that priming with pain-related words increases pain ratings to subsequent noxious target stimuli compared with priming with negative words. These hypotheses were investigated with respect to varying ISIs and pain intensities.

\section{Main effects of factors Category and Intensity}

In accordance with our expectations, an overall negative priming effect of pain-related and negative primes for the processing of subsequent noxious stimuli compared with neutral primes appeared as a main effect of factor Category. This finding is consistent with studies showing a negative emotional priming effect induced by unpleasant visual stimuli $(8-10,41)$. According to the present study, we conclude that semantic stimuli with distinct negative valence exert negative priming on the processing of succeeding painful stimuli. According to the motivational priming theory, this may be due to the activation of neural structures associated with negative affect (13).

Concerning hypothesis 2, we did not find a main effect indicating a significant difference in pain ratings following pain-related compared with negative primes.

The main effect for Intensity indicates that the establishment of two distinct pain intensities, one mild and one medium pain intensity, during the experiment was successful.

Interaction effects among the factors Category, Intensity and ISI In the ANOVA, we found an interaction among all three factors. The following simple interaction effect analyses, one for each Intensity, revealed an interaction for Category $\times$ ISI only during the condition in which noxious stimuli were of moderate pain intensity (Int2), but not when intensity was mild (Int1). Thus, word stimuli describing pain-related adjectives appear to affect the processing of painful stimuli only when the stimulus is clearly painful. This finding is in accordance with results of a study performed by Godinho et al (27). These authors also found priming effects for clearly painful electrical stimulation, but no influence for intensities lightly beyond the pain threshold. Taking these data as well as a study from Kenntner-Mabiala and Pauli (9) also demonstrating a priming effect of negative pictures (compared with neutral pictures) for painful electrical stimulation, priming effects of context must be considered for painful electrical stimuli. These effects may be stronger the higher the pain intensity.

Additionally, a negative priming effect for Int 2 was found when the ISI between verbal prime and electrical stimulus was short (ISI 500) or when the prime was immediately followed by the stimulus (ISI 0), supporting our first hypothesis. Previous studies also found distinct priming effects when the target pain stimulus was presented immediately after or during prime presentation $(10,27,28,40)$. Similarly, studies investigating semantic priming indicate that the semantic priming effect loses magnitude during prolonged time

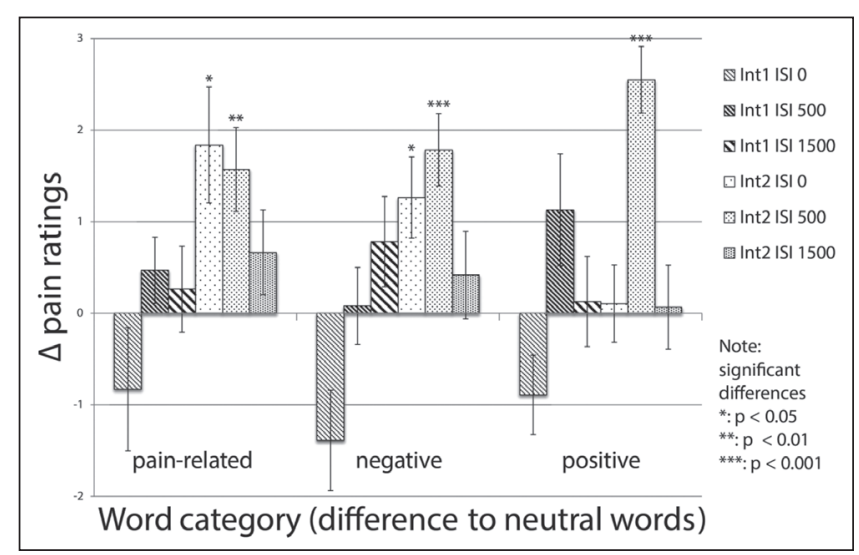

Figure 4) Mean differences in pain ratings ( $\Delta$ pain ratings) and SEs to noxious stimuli primed by adjectives (factor word Category) with respect to the factors Intensity (Int) and interstimulus interval (ISI). Differences are shown in comparison with priming with neutral adjectives. Positive values indicate higher pain ratings for the priming with the particular category in comparison with neutral adjectives; asterisks indicate significant changes compared with neutral adjectives

intervals between prime and target $(42,43)$. In a study investigating the affective priming effect of pain-related pictures on reaction times during categorization of subsequent negative words (44), the priming effect was only present when target stimulus was presented $300 \mathrm{~ms}$ after onset of the prime, but not after $500 \mathrm{~ms}$ or $1000 \mathrm{~ms}$. At least in part, our results support the assumption of these authors, concluding that affective priming is a rapid and automatic cognitive process that may be alleviated by higher cognitive processes such as working memory or resting-state processes commencing quickly after prime onset.

The priming effect for ISI 0 may be affected by processes investigated under the term of attentional blink. In a series of experiments, it was demonstrated that the processing and recognition of a second target stimulus that follows a first target stimulus becomes significantly disturbed within a time window of approximately $500 \mathrm{~ms}$ after onset of the first stimulus $(45,46)$. During ISI 0 , the noxious target stimulus was presented during the time interval of the attentional blink; more precisely, $300 \mathrm{~ms}$ after onset of the prime stimulus. The processing of the noxious stimulus may, therefore, be impaired by this process. However, it has been shown that the attentional blink is attenuated when the second stimulus is of negative affective valence (47) or semantically related to the first stimulus $(48,49)$. Consequently, this effect may be reduced when the previously presented prime is of the same affective quality or is associated semantically with the noxious stimulus. The higher pain ratings we found during negative and pain-related priming compared with neutral priming may, therefore, be related to a weakened attentional blink effect. However, during ISI 500 as compared with ISI 0 , we found reduced pain ratings beyond all categories (except for the positive words) and a similar significant difference between pain ratings following negative affective and neutral primes. During ISI 500 (ie, $800 \mathrm{~ms}$ after prime onset, processes related to the attentional blink ought to be completed). Therefore, the attentional blink appears to play a minor role for the explanation of our results.

As expected, pain intensity ratings were significantly lower after neutral and positive primes versus negative and pain-related primes for ISI 0. However, for ISI 500, pain ratings after positive primes were elevated compared with neutral primes. For this ISI, positive primes appeared to have a negative priming effect similar to negative and pain-related primes, resulting in increased pain ratings compared with neutral stimuli. The N400, occurring between $300 \mathrm{~ms}$ and $500 \mathrm{~ms}$ after the presentation of a linguistic stimulus, is assumed to reflect semantic processing of the stimulus (50). According to Li et al (51), the N400 amplitude is increased after the presentation of incongruent verbal stimuli. It is assumed that this $\mathrm{N} 400$ increase is due to the semantic 
conflict between the primes. In our study, a semantic conflict may emerge between the positive valence of the prime and the expectation of a negative pain stimulus for the ISI of $500 \mathrm{~ms}$. This cognitive conflict may itself serve as a negative prime during ISI 500 and, therefore, elevate the following pain rating, similar to the negative and painrelated primes.

As mentioned above, we did not find a main effect indicating a significant difference in pain ratings following pain-related compared with negative primes. For ISI $0 \mathrm{~ms}$, the assumed effect is shown descriptively but failed to reach statistical significance. Previous studies investigating healthy subjects during priming with affective pictures reported a larger effect for pain-related primes compared with negative, pain-unrelated primes on intensity ratings of succeeding electrical stimuli $(27,28)$ or on pain tolerance threshold measured by the cold pressor test (14). Regarding the fact that mean pain rating for Int 2 indicated that intensity was perceived to be relatively mild, we presume that the priming effect of pain-related words may have been more pronounced for higher pain intensities, as indicated by a previous study (27).

\section{Limitations and future directions}

Our study demonstrated very systematic effects of priming. However, the effect sizes were relatively small. Participants of the present study were healthy young individuals. It appears that the category of the primes plays a minor role in modulating the perception of noxious stimuli in this particular group. There are clues indicating that the priming effects of pain-related primes versus negative, pain-unrelated primes are more pronounced in chronic pain patients compared with healthy controls $(21,28)$. It appears that subjects with repeated pain experiences, such as subjects with a chronic pain disease, have developed stronger associative learning networks during incremental experiences and, therefore, show larger priming effects after receiving pain-related primes versus negative, pain-unrelated primes. Investigation of priming in chronic pain patients should clarify this issue.

In the present study, four categories of words were used, each consisting of 10 different adjectives. The acquisition of a greater variety of different matching primes could support the generalization of the findings. Furthermore, priming may be more potent for images. We did not find a significant difference in pain ratings for pain-related versus negative pain-unrelated stimuli, in contrast to de Wied and Verbaten (14) and Ogino et al (15). Therefore, emotional and pain-related pictures may be better for the investigation of principle mechanisms of priming in humans. However, this does not preclude the necessity of investigating the extent of verbal priming in chronic pain patients. There are already hints that the effects are stronger than in healthy subjects (21).

Although two distinct pain intensities were successfully established, the manipulation of the moderate pain intensity resulted in a relatively mild average pain rating. This could be one of the reasons why some of the assumed effects for the differences between negative and pain-related adjectives failed to reach statistical significance. It may be a challenge for future research on electrical pain stimulation to solidly apply moderate pain intensities to clearly distinguish them from mild or no pain intensities. One way of doing so may be a bioadaptive approach, as proposed previously (26).

\section{CONCLUSION}

Semantic priming was investigated by using negative and pain-related stimuli that were matched for valence and arousal. In accordance with the motivational priming theory, we found stronger pain ratings for subsequent electrical stimuli after negative and pain-related priming compared with neutral priming. These effects were especially apparent for stronger intensities of the painful stimulation and when the interval between prime and target stimulus was $\leq 500 \mathrm{~ms}$. Further studies are necessary to examine whether this trend indicates a specific effect according to the theory of associative neural networks.

ACKNOWLEDGEMENTS AND FUNDING: Research was partly funded by the BMBF (German Federal Ministry of Research and Technology, Bernstein Group 01GQ0703 and 01EC1003) and the IZKF (Interdisciplinary Center for Clinical Research) of the Friedrich Schiller University (Jena, Germany).

\section{REFERENCES}

1. Friederich M, Trippe RH, Ozcan M, Weiss T, Hecht H, Miltner WH. Laser-evoked potentials to noxious stimulation during hypnotic analgesia and distraction of attention suggest different brain mechanisms of pain control. Psychophysiology 2001;38:768-76.

2. Klossika I, Flor H, Kamping S, et al. Emotional modulation of pain: A clinical perspective. Pain 2006;124:264-8.

3. Miltner WH, Johnson R, Braun C, Larbig W. Somatosensory eventrelated potentials to painful and non-painful stimuli: Effects of attention. Pain 1989;38:303-12.

4. Rainville P, Bao QV, Chretien P. Pain-related emotions modulate experimental pain perception and autonomic responses. Pain 2005;118:306-18.

5. Straube T, Schmidt S, Weiss T, Mentzel H-J, Miltner WH. Sex differences in brain activation to anticipated and experienced pain in the medial prefrontal cortex. Hum Brain Mapp 2009;30:689-98.

6. Villemure C, Bushnell MC. Mood influences supraspinal pain processing separately from attention. J Neurosci 2009;29:705-15.

7. Villemure C, Schweinhardt P. Supraspinal pain processing: Distinct roles of emotion and attention. Neuroscientist 2010;16:276-84.

8. Bartley EJ, Rhudy JL. The influence of pain catastrophizing on experimentally induced emotion and emotional modulation of nociception. J Pain 2008;9:388-96.

9. Kenntner-Mabiala R, Pauli P. Affective modulation of brain potentials to painful and nonpainful stimuli. Psychophysiology 2005;42:559-67.

10. Meagher MW, Arnau RC, Rhudy JL. Pain and emotion: Effects of affective picture modulation. Psychosom Med 2001;63:79-90.

11. Montoya P, Sitges C. Affective modulation of somatosensoryevoked potentials elicited by tactile stimulation. Brain Res 2006;1068:205-12.

12. Rhudy JL, Williams AE. Gender differences in pain: Do emotions play a role? Gend Med 2005;2:208-26.

13. Lang PJ. The emotion probe - studies of motivation and attention. Am Psychol 1995;50:372-85.

14. de Wied M, Verbaten MN. Affective pictures processing, attention, and pain tolerance. Pain 2001;90:163-72.

15. Ogino Y, Nemoto H, Inui K, Saito S, Kakigi R, Goto F. Inner experience of pain: Imagination of pain while viewing images showing painful events forms subjective pain representation in human brain. Cereb Cortex 2007;17:1139-46.

16. Miltner WH, Braun C, Arnold M, Witte H, Taub E. Coherence of gamma-band EEG activity as a basis for associative learning. Nature 1999;397:434-6.

17. Hebb DO. The Organisation of Behaviour. Wiley, New York, 1949.

18. Melzack, R. From the gate to the neuromatrix. Pain 1999;82:121-6.

19. Pulvermuller F. Brain reflections of words and their meaning. Trends Cog Sci 2001;5:517-24.

20. Pulvermuller F, Fadiga L. Active perception: Sensorimotor circuits as a cortical basis for language. Nat Rev Neurosci 2010;11:351-60.

21. Eck J, Richter M, Straube T, Miltner WH, Weiss T. Affective brain regions are activated during the processing of pain-related words in migraine patients. Pain 2011;52:1104-13.

22. Gu X, Han S. Neural substrates underlying evaluation of pain in actions depicted in words. Behav Brain Res 2007;181:218-23.

23. Richter M, Eck J, Straube T, Miltner WH, Weiss T. Do words hurt? Brain activation during the processing of pain-related words. Pain 2010;148:198-205.

24. Dorjee D, Devenney L, Thierry G. Written words supersede pictures in priming semantic access: A P300 study. Neuroreport 2010;21:887-91.

25. Dillmann J, Miltner WHR, Weiss T. The influence of semantic priming on event-related potentials to painful laser-heat stimuli in humans. Neurosc Lett 2000;284:53-6. 
26. Weiss T, Miltner WH, Dillmann J. The influence of semantic priming on event-related potentials to painful laser-heat stimuli in migraine patients. Neurosci Lett 2003;340:135-8.

27. Godinho F, Magnin M, Frot M, Perchet C, Garcia-Larrea L. Emotional modulation of pain: Is it the sensation or what we recall? J Neurosci 2006;26:11454-61.

28. Arnold BS, Alpers GW, Süß H, Friedel E, Kosmützky G, Geier A, Pauli P. Affective pain modulation in fibromyalgia, somatoform pain disorder, back pain, and healthy controls. Eur J Pain 2008;12:329-38.

29. Liossi C, Schoth DE, Bradley BP, Mogg K. Time-course of attentional bias for pain-related cues in chronic daily headache sufferers. Eur J Pain 2009;13:963-9.

30. Hauk O, Shtyrov Y, Pulvermuller F. The time course of action and action-word comprehension in the human brain as revealed by neurophysiology. J Physiol Paris 2008;102:50-8.

31. Kissler J, Assadollahi R, Herbert C. Emotional and semantic networks in visual word processing: Insights from ERP studies. Prog Brain Res 2006;156:147-83.

32. Rayner K, Clifton C Jr. Language processing in reading and speech perception is fast and incremental: Implications for event-related potential research. Biol Psychol 2009;80:4-9.

33. Barber HA, Kousta ST, Otten LJ, Vigliocco G. Event-related potentials to event-related words: Grammatical class and semantic attributes in the representation of knowledge. Brain Res 2010;1332:65-74.

34. Sereno SC, Rayner K, Posner MI. Establishing a time-line of word recognition: Evidence from eye movements and event-related potentials. Neuroreport 1998;9:2195-200.

35. Hautzinger M, Kühner C, Keller F. BDI-II Beck-DepressionsInventar. Harcourt Test Services, Frankfurt, 2006.

36. Bromm B, Meier W. The intracutaneous stimulus: A new pain model for algesimetric studies. Methods Find Exp Clin Pharmacol 1984;6:405-10.

37. Meissner W, Weiss T, Trippe RH, Hecht H, Krapp C, Miltner WH. Acupuncture decreases somatosensory evoked potential amplitudes to noxious stimuli in anesthetized volunteers. Anesth Analg 2004;98:141-7.

38. Ellermeier W, Westphal W, Heidenfelder M. On the absoluteness of category and magnitude scales of pain. Percept Psychophys 1991;49:159-66.
39. Ellermeier W, Westphal W. Gender differences in pain ratings and pupil reactions to painful pressure stimuli. Pain 1995;61:435-9.

40. Weiss T, Kumpf K, Ehrhardt J, Gutberlet I, Miltner WH. A bioadaptive approach for experimental pain research in humans using laser-evoked brain potentials. Neurosci Lett 1997;227:95-8.

41. Bufalari I, Aprile T, Avenanti A, Di Russo F, Aglioti SM. Empathy for pain and touch in the human somatosensory cortex. Cereb Cortex 2007;17:2553-61.

42. Spencer KA, Wiley E. Response priming patterns differ with interstimulus interval duration. Clin Ling Phon 2008;22:475-90.

43. Versace R, Nevera B. Word frequency effect on repetition priming as a function of prime duration and delay between the prime and the target. Brit J Psychol 2003;94:389-408.

44. Goubert L, Crombez G, Hermans D, Vanderstraeten G. Implicit attitude towards pictures of back-stressing activities in pain-free subjects and patients with low back pain: An affective priming study. Eur J Pain 2003;7:33-42.

45. Dux PE, Marois R. The attentional blink: A review of data and theory. Atten Percept Psychophys 2009;71:1683-700.

46. Shapiro K, Narayanan S. The functional architecture of divided visual attention. Prog Brain Res 2009;176:101-21.

47. Trippe RH, Hewig J, Heydel C, Hecht H, Miltner WH. Attentional blink to emotional and threatening pictures in spider phobics: Electrophysiology and behavior. Brain Res 2007;1148:149-60.

48. Harris IM, Little MJ. Priming the semantic neighbourhood during the attentional blink. PLoS One 2010;5:1-6.

49. Maki WS, Frigen K, Paulson K. Associative priming by targets and distractors during rapid serial visual presentation: Does word meaning survive the attentional blink? J Exp Psychol Hum Percept Perform 1997;23:1014-34.

50. Friederici AD. The brain basis of language processing: From structure to function. Physiol Rev 2011;91:1357-92.

51. Li X, Shu H, Liu Y, Li P. Mental representation of verb meaning: Behavioral and electrophysiological evidence. J Cogn Neurosci 2006;18:1774-87. 


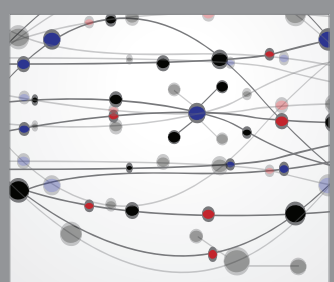

The Scientific World Journal
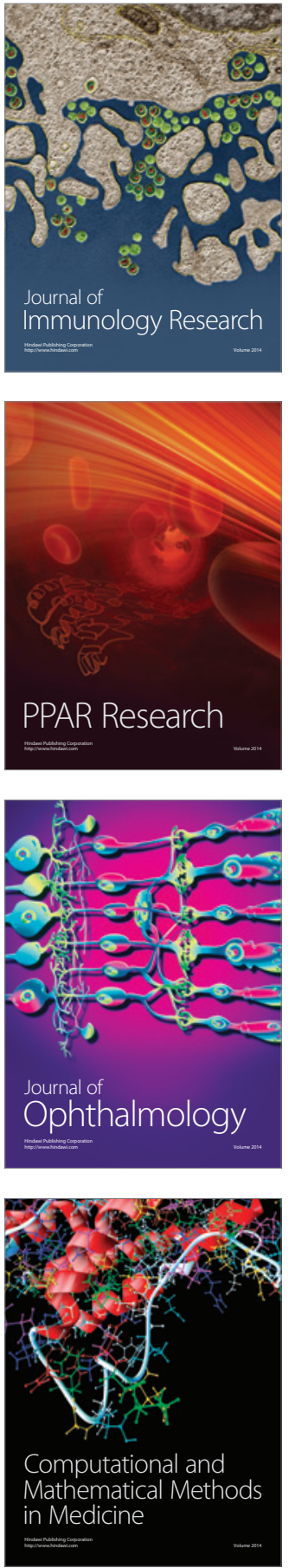

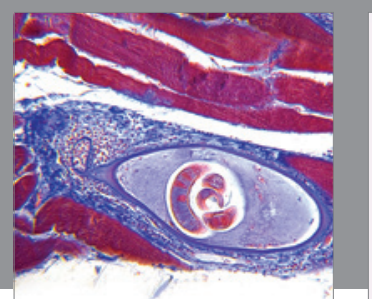

Gastroenterology Research and Practice

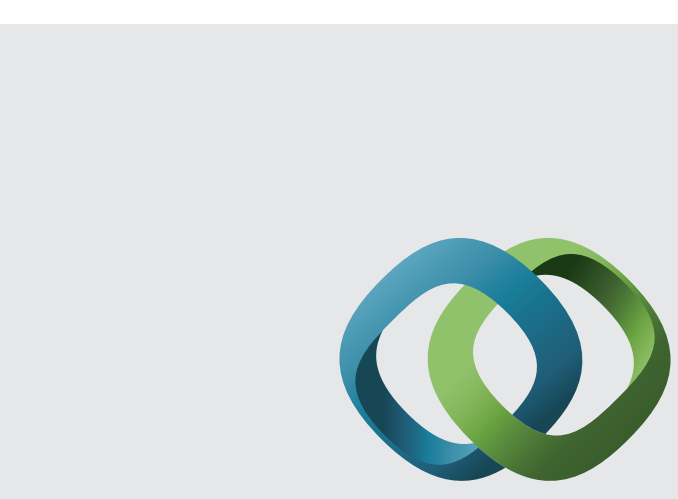

\section{Hindawi}

Submit your manuscripts at

http://www.hindawi.com
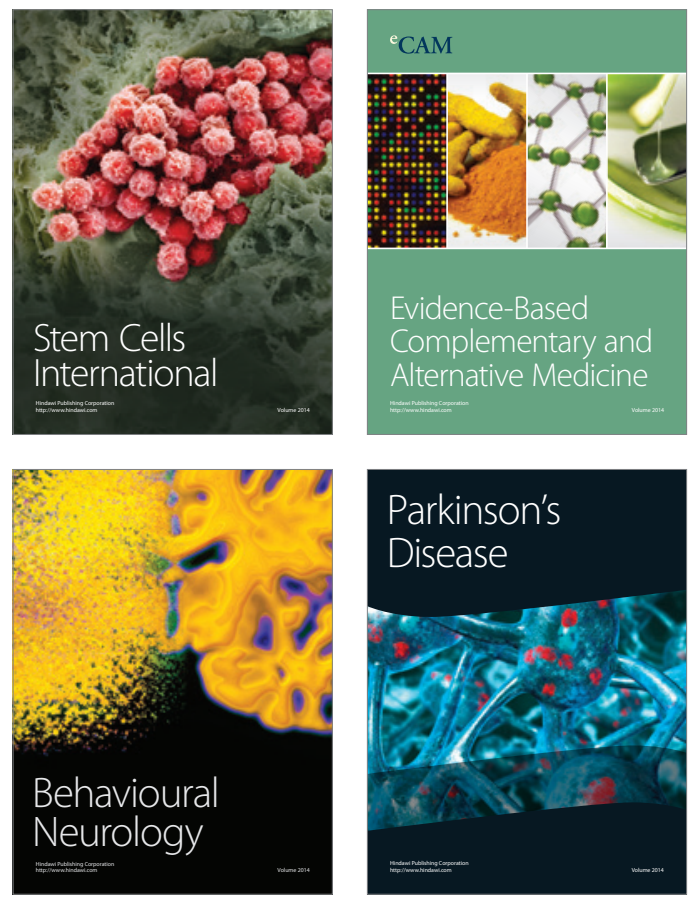
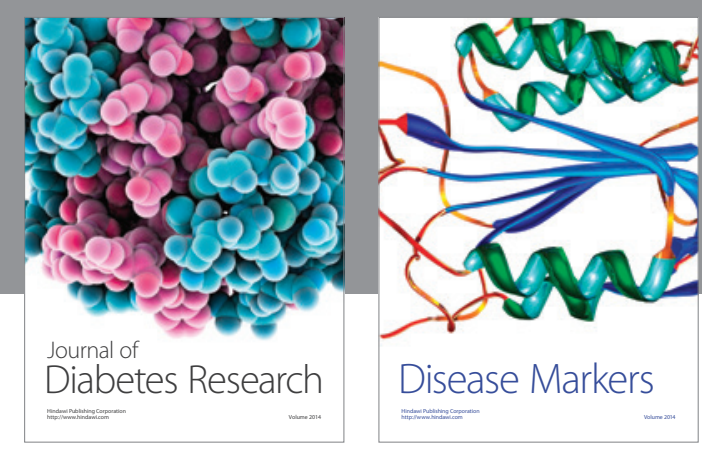

Disease Markers
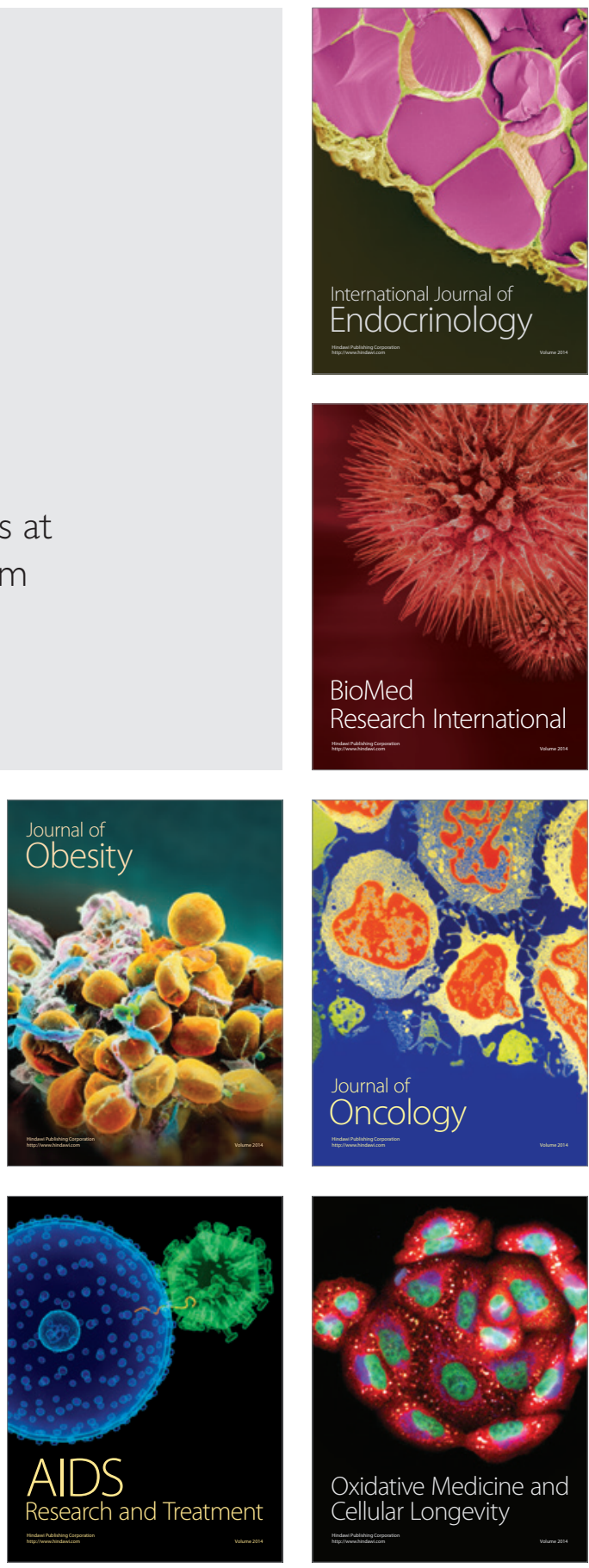